\title{
Wittgenstein, Dewey, and the Practical Foundation of Knowledge
}

Jörg Volbers

\section{CpenEdition}

\section{Journals}

Electronic version

URL: http://journals.openedition.org/ejpap/724

DOI: $10.4000 /$ ejpap.724

ISSN: 2036-4091

\section{Publisher}

Associazione Pragma

\section{Electronic reference}

Jörg Volbers, « Wittgenstein, Dewey, and the Practical Foundation of Knowledge », European Journal of Pragmatism and American Philosophy [Online], IV-2 | 2012, Online since 24 December 2012, connection on 08 May 2019. URL : http://journals.openedition.org/ejpap/724 ; DOI : 10.4000/ejpap.724

This text was automatically generated on 8 May 2019.

\section{(c) $\Theta \Theta \Theta$}

Author retains copyright and grants the European Journal of Pragmatism and American Philosophy right of first publication with the work simultaneously licensed under a Creative Commons AttributionNonCommercial-NoDerivatives 4.0 International License. 


\title{
Wittgenstein, Dewey, and the Practical Foundation of Knowledge
}

\author{
Jörg Volbers
}

In our time, when classical philosophy of language has long lost its sovereign position in the philosophical field, it is no longer surprising nor unusual to classify Wittgenstein (his later works) and Dewey as both belonging to the same family of pragmatists, understood in a broad sense. ${ }^{1}$ They both express a common position which can be roughly defined as claiming 'the primacy of practice.' They argue that certain subjects of philosophical discussion, such as meaning, logical necessity, intentionality and understanding, have to be understood as primarily rooted, or anchored, in our practical sayings and doings. If we want to improve our understanding of what we actually do and believe, we have to look at practice.

Given this background, it is nonetheless surprising how different in form and outlook their philosophies are. The differences in style immediately catch one's eye. Wittgenstein's writings have often been credited with a highly poetical quality. His thinking is divided into short, sometimes aphoristic paragraphs; he uses questions, elliptical remarks, and dialogue; he employs images and similes; he does not quote nor discuss opposing theories explicitly. Dewey, for his part, is much more professional in this respect. He wrote books, treatises and short essays in which he continuously developed his central themes and presented them in a (more or less) systematic manner. He suggested answers to classical philosophical problems and argued against dissenting theories. The poetic ring of mysticism and aphorism is rather alien to his literary style. Russell Goodman gives us an accurate picture of the experience of reading Dewey: "Dewey, I always feel, talks at, rather than to, or with, his readers" (Goodman 2002: 165). It is exactly the impression of being spoken to that distinguishes Wittgenstein's writing when it is at its best. He draws the reader into his thought, which, by the way, can also be rather disorienting.

3 These differences in style correspond to a rather fundamental divergence in their principal outlook. Dewey was, like the pragmatist movement in general, keenly optimistic about the possibility of making the world a better place. He advocated the power of 
reflection and praised the progress of experimental science as a paradigm for reflective thinking, inquiry, in general. Wittgenstein was a cultural pessimist. He also saw 'our civilization' as characterized by progress, but he expressed deep mistrust about the idea. The Philosophical Investigations begins with a quotation from Nestroy: "Progress always appears much greater than it actually is." Even though one might argue about whether Wittgenstein's thinking is inherently conservative, ${ }^{2}$ it is surely, as von Wright put it, "anything but 'prophetic.' It has no vision of the future; rather it has a touch of nostalgia about the past" (Von Wright 1982: 115).

4 How should we judge these differences in style and outlook? It would be superficial to simply dismiss them, especially if one adopts a pragmatic way of thinking. If the primacy of practice has any value, then it is to remind us that the way we do things is not secondary to the things done. But then, of course, it would be equally superficial just to take these first impressions at face value. My thesis is that they point to a more substantial difference, one which concerns the very core of their philosophies. Even though both are concerned with the primacy of practice, they have quite a different understanding of what this appeal to practice, in the end, amounts to. So the difference I am aiming at actually concerns the very idea of philosophy itself, as both 'pragmatists in the broad sense' understand it. What does it mean to 'look at the language-games,' as Wittgenstein urges us? Why should we put our trust in experience and action, as Dewey invites us?

These methodological questions can be reformulated in a way that allows us to treat them more directly. The problem is: What is it that we expect from philosophy, what do we want to learn from engaging in it? What knowledge, or what kind of knowledge, does philosophy provide? In particular: What kind of knowledge does the appeal to practice provide? The topic of knowledge is omnipresent in both philosophers' writings. Their being classified as belonging to one broad family of pragmatists owes a great deal to the fact that they develop quite parallel views of what knowledge is, and what it cannot be. Here is the short story: Both Wittgenstein and Dewey criticize the traditional philosophical idea that knowledge is a distinctively mental phenomenon, something residing in a 'subject' which is categorically divided from the world it is acting upon, the 'object.' The world is not something which is 'viewed' from the outside, as it were. Instead of indulging in the futile "spectator theory of knowledge," they instead put the emphasis on the necessary connection between knowledge, on the one side, and skills, habits, or capacities on the other. Wittgenstein writes: "Knowledge is an ability"; 3 Dewey follows the pragmatist tradition in arguing that knowledge is primarily embodied in flexible habits. It is practice which comes first, be it in the form of habits, skills, language-games or (as Dewey likes to call it) 'conjoint behaviour.' What we experience is a product of this practical involvement, not the other way around. No surprise then that pragmatism (in the broad sense) has been claimed to be right in the line of Kantian transcendental philosophy, albeit with a realist leaning (Pihlström 2004).

6 Seen from this perspective, Wittgenstein's 'pessimism' as well as Dewey's 'optimism' regarding progress can be seen as expressing a different attitude toward this practically embedded knowledge. Stanley Cavell had a good eye for that. What is missing in pragmatism, he wrote, is a sensitivity for 'the depth of the human restiveness' (Cavell 2004: 3). Varying upon a theme that he has more systematically exposed in the first part of his Claim of Reason, Cavell uses the subject of knowledge in order to demonstrate what he means by this. What singles out Wittgenstein as an opponent of pragmatism, Cavell 
claims, is the former's attitude toward knowledge. Cavell describes it as a 'disappointment,' one which is akin to to skepticism, but yet substantially different: Wittgenstein's disappointment with knowledge is not that it fails to be better than it is (for example immune to skeptical doubt), but rather that it fails to make us better than we are, provide us with peace. (Cavell 2004: 3)

7 Two conclusions can be drawn from this statement. Its first is that pragmatism upholds the belief in knowledge; it hopes that knowledge can 'make us better than we are.' Conversely, Cavell holds that Wittgenstein sees a limit to the capacity of knowledge, limits which affect his philosophy as a whole. These two conclusions do not only align with the differences in philosophical outlook with which this paper began - Dewey putting his trust in science and progress, Wittgenstein mistrusting it deeply. It will also explain, I believe, their differences in style and finally in method. Thus, the pragmatic conception of knowledge which is shared by both authors - that knowledge is somehow 'constituted' through practice, or 'embedded' in it - turns out to be the pivotal point from which to assess their respective differences.

8 I will begin, then, by elaborating Dewey's understanding of knowledge and practice, always keeping an eye on the question concerning the implications it has for the role of philosophy (Cavell's 'making us better than we are'). I will then turn to Wittgenstein and try to show how his latest remarks, collected in On Certainty (1968), support Cavell's judgment. In these remarks Wittgenstein introduces a distinction which is foreign to Dewey, namely, that we might well have practically upheld "certainties" which do not correspond to knowledge, that is, that neither express it nor stand in an instrumental relation to it. These certainties point to other ways we are related to the world and to others. I will call this Wittgenstein's discovery of the essentially social dimension of practice. For him, our practical standing in the world is not primary upheld by practically acquired certainties, but by the dynamic net of responses, expectations and disappointments in which we are embedded. Knowledge and inquiry, from this point of view, lose their sovereign position as the most serious game in the town.

\section{Dewey's Inquiry Into Inquiry}

9 Does it make any sense to say that for Dewey knowledge 'makes us better than we are,' as Cavell's statement implies? Dewey's characterizations of knowledge and knowing are ambiguous in that respect. There is, for one, his straight rejection of a philosophical tradition which conceives of knowledge in terms that are all too high and too theoretical. Following the well-trodden path of religion, philosophy had detached theoretical activities from practice, placing itself firmly on the side of theory. It took thinking to be a contemplative art, theoria in the Greek sense, dealing "with a realm of higher Being" (Dewey 1988: 11). Knowledge, then, is thought of as being something immutable, something which ideally does not change and thus provides us with insights into reality as it is. 'Knowing,' in the traditional sense, as Dewey reconstructs and criticizes it, can thus serve a fundamental need: It provides a means to fulfil the human, all-too-human, 'Quest for Certainty' by giving the knower access to something which holds fast. It establishes a certainty which is beyond all doubt. The doctrine of 'pure knowing' thus forms an essential part of the tradition Dewey criticizes: "Quest for complete certainty can be fulfilled in pure knowing alone. Such is the verdict of our most enduring philosophic tradition" (Dewey 1988: 7). 
Dewey's criticism of this traditional conception of knowledge is a fine example of dialectical reasoning. He does not argue directly against the 'Quest for Certainty,' but rather tries to show that it fails on its own terms. The knowledge it seeks, Dewey claims, cannot be had because we cannot rid ourselves of uncertainty. Uncertainty is the "distinctive characteristic of practical activity [...] of it we are compelled to say: Act, but act at your own peril. Judgment and belief regarding actions to be performed can never attain more then precarious probability" (Dewey 1988: 5). This is not a direct refutation of the traditional claim, since it leaves intact the possibility that we shift the grounds. A defender of the tradition might argue that we have to concentrate on theoretical knowledge precisely because Dewey's characterization of practical activity is correct. Dewey's task, then, is to point out that this conclusion rests on an untenable dualistic separation of these two 'realms' of theory and practice. One important argument to that purpose is Dewey's historical claim that this separation reflects a mere cultural prejudice. The high esteem of theory conforms to the values of a social elite which devalues and depreciates the activities of those "lower" classes on which it depends (Dewey 1988: 21-39). If we drop that prejudice, we will see that the separation between knowledge and action has no real grounds - theory is also an activity.

11 Having reached this point, one might conclude that Dewey invites his readers to completely dismiss the traditional estimation of knowledge. Being on a par, both theory and practice have to rely on a disloyal 'practical activity.' Does this not imply that the inherent uncertainty of practice also extends to theoretical activities? Here the ambiguity of Dewey's position becomes visible. He rejects the traditional praise of 'pure knowing,' but he still holds knowledge in high esteem. What has changed is the ground upon which we assert the value of knowledge. For Dewey, the destruction of the traditional barrier between knowledge and action frees our minds for a better (or more justified) appraisal of knowledge's real value. It helps us to see that we do, as a matter of fact, possess quite numerous certainties. There is knowledge; but it cannot be found where philosophy has looked for it. It is embodied in those impure and ordinary works of artisanry which have been ignored by the tradition. ${ }^{4}$ As opposed to philosophers, these practitioners do not waste their time with "framing a general theory of reality, knowledge and value once for all," but are rather occupied with "finding how authentic beliefs about existence as they currently exists can operate fruitfully and efficaciously" (Dewey 1988: 36). These men and women just act, and in acting, they devise tools, understanding and values. ${ }^{5}$

It is a misunderstanding to believe that Dewey's philosophy glorifies science. Science, for Dewey, is important because it best exemplifies the general pattern exhibited by these practical activities. The tremendous success of science is not based on its superior mode of reflection or ratiocination in the way traditional philosophy understands it, but rather on its picking up the impure methods and practical inclinations of artisanry. ${ }^{6}$ Experimental science embodies "the actual procedures of knowledge" (Dewey 1988: 38) and thus form the model of what Dewey considers to be the one and only way to gain knowledge in the face of the uncertainties of practice. This pattern, as it is well known, is called inquiry.

13 I have taken the trouble to establish such a well-known key-concept of Dewey's philosophy in order to show how utterly realistic his understanding of knowledge is. This is not intended to mean that he has 'found the right thing,' but rather that his trust in the power of inquiry is firmly based on facts (or so he claims). Dewey's method aims at confronting philosophical presumptions with what he considers to be a more realistic 
picture of what we do. If the topic in question is knowledge, we have to go and look at the actual procedures in which knowledge is gained. Instead of defining knowledge beforehand and then looking for its manifestations, we will rather gain a better understanding of what we are actually looking for by first looking at the practices in which knowledge is operative. "The fundamental advantage of framing our account of the organs and processes of knowing on the pattern of what occurs in experimental inquiry is that nothing is introduced save what is objective and is accessible to examination and report" (Dewey 1988: 183).

This whole procedure bears a close resemblance to Wittgenstein. Dewey would have agreed upon statements like the following, which can be found in the Philosophical Investigations: "For our forms of expression prevent us in all sorts of ways from seeing that nothing out of the ordinary is involved, by sending us in pursuit of chimeras" (Wittgenstein 1969: sec. 94). Knowledge, we could say, is nothing out of the ordinary, it is there, and the traditional mistake is to assume that knowledge must have a specifally 'pure' form. Rather, it is the ordinary use - embodied in actual practice - which shows us how the phenomenon in question is really to be taken. I take this to be the gist of what Dewey calls his 'denotative' or 'empirical' method. In adopting for a realistic attitude, we are not to begin with the "results of reflection" (Dewey 1981: 19), but rather look at how reflection is done.

But there is a certain twist to Dewey's approach which, as we will see, sets him apart from Wittgenstein. Knowledge, for Dewey, is not just some conception among others to which we can turn. To a pragmatist's ear, Cavell's contention that knowledge 'makes us better than we are' must sound like a tautology. For Dewey, such a claim comes close to a definition of what knowledge can sensibly be. Inquiry is always an attempt to improve our situation and eventually our place in the world: "Anything that may be called knowledge, or a known object, marks a question answered, a difficulty disposed of, a confusion cleared up, an inconsistency reduced to coherence, a perplexity mastered" (Dewey 1988: 181).

16 Two aspects are important here. For one, Dewey's understanding of inquiry has the effect of insulating the uncertainties immanent to practice. Doubt is, as it were, only possible locally; it arises in the form of problems within the confines of the objective 'situation' (as Dewey calls it). Following Peirce, Dewey's general pattern of inquiry assumes that we act with full certainty, and it is the goal of inquiry to regain this capacity. The second point is that inquiry, as Dewey understands it, is always a response to an objectively problematic situation. Inquiry is not an idle, isolated activity. It is an essential part in our struggle to cope with all the uncertainties that permeate our practical activities. We are obliged to inquire.

17 The ubiquity of inquiry is obvious for those pre-intellectual, more or less subconscious forms of reflective inquiry that are at work in our continuous bodily interaction with the environment. But Dewey expands this pattern to include those elaborated practices by which we consciously try to solve problems. To be sure, there is a decisive difference between these two poles of inquiry: intellectual inquiry is dependent on the use of language, broadly understood as the capacity to use signs which embody meaning. It allows the inquiring subject to relate the currently experienced traits of the situation to past and future ones; it introduces rational discourse and the capacity to form distinctive ideas about what to expect and what to do. But that modification, though it introduces a 
significant qualitative change, is according to Dewey but an extension of the original organic disposition towards reflective interaction with the environment. ${ }^{7}$

This short synopsis shows that knowledge, for Dewey, is something we cannot not have. Inquiry is hardwired into our biological and cultural pattern of life; it is the principal instrument of survival. It is the origin of all the certainties we have at our disposal. If there is some stability and knowledge in a world that condemns us to act at our own peril, it is the result of the inquiries which permeate our organic life and which define our current place in history.

As we have seen, the methodological justification for this view is the idea that in 'inquiring into inquiry,' we are de facto just looking at what we really do. What is curious, though, is that the result of this operation echoes the very idea from which it critically parted: "The quest for certainty," Dewey writes, "is a quest for a peace which is assured, an object which is unqualified by risk and the shadow of fear which action casts" (LW4: 7). In the context of this passage, it becomes clear that Dewey rejects this quest, belonging to the faulty doctrine of 'pure knowing.' But what does Dewey's philosophy offer us, if not a new reason to find peace again? For the tradition, the quest for peace has been directed towards the objects of knowledge. For Dewey, reassurance can be found in the truth of inquiry. 'Pure knowledge' proves to be a quasi-religious dogma, but knowledge in the pragmatic sense is everywhere. In submitting all knowledge to situational inquiry, Dewey creates a stable frame wherein the content of inquiry might change, but in its very form it remains stable.

We have seen that Dewey's attitude towards knowledge and 'peace' has two sides. His whole philosophical outlook is based on the idea that every practical activity is threatened by uncertainty; we live in an instable world in which we cannot attain the kind of knowledge the tradition has looked for. But at the same time, this very contingency also forms our capacity to reflect. ("But where danger is/Deliverance also grows," Hölderlin would remark.) Inquiry itself is not a contingent practice, but the very pattern by which life upholds itself. Inquiry and contingency are two sides of the same coin. In the end, our knowledge is as certain as anything can be in this precarious world. If we accept the world's contingencies (by turning our back to the false demands of an elitist tradition), we can again gain the peace philosophy has always been looking for.

\section{Wittgenstein's Remarks On Certainty}

21 For Dewey, knowledge indeed does make us better and also provides us with some (nontraditional) form of peace. Now it is time to investigate Wittgenstein's attitude towards knowledge and certainty. We set out with Cavell's claim that Wittgenstein, as opposed to pragmatists such as Dewey, was 'disappointed' with the delivering potential of knowledge. This subject has been extensively treated by Cavell under the heading of 'skepticism.' For Cavell, Wittgenstein is not a skeptic in the classical epistemological sense. He rather articulates the 'truth' of skepticism, which is, according to Cavell, that "our relation to the world as a whole, or to others in general, is not one of knowing, where knowing construes itself as being certain" (Cavell 1979: 45).

The way Cavell reads Wittgenstein, an interesting contrast with Dewey's position emerges. Both Wittgenstein and Dewey seem to be occupied with the problem of certainty and its relation to knowledge, and both can be seen as acknowledging a certain truth to 
skepticism..$^{8}$ Of course, neither Dewey nor Wittgenstein are straightforward skeptics. ${ }^{9}$ But Dewey's whole philosophy is based on the assumption that uncertainty is irrefutable, and the presence of an encompassing state of doubt is Dewey's definition of the beginning of inquiry (Dewey calls it "the indeterminate situation," cf. Dewey 2008: 109-11). So we might say that Dewey transforms skepticism, tames it, as it were.

In order to see how Wittgenstein treats the topic of certainty, and how it contrasts with Dewey, let us now turn to the collection of remarks which bears it in the title. On Certainty is not a book which Cavell has discussed extensively, but I believe it can well illustrate the very point Cavell - or Wittgenstein - is up to. There has been quite some discussion about the right way to read On Certainty, and it has been argued that this last book represents a new phase in his thinking, called the 'third Wittgenstein. ${ }^{10}$ I will concentrate here on one point that particularly attracts attention: Wittgenstein's style of argumentation is reminiscent of transcendental philosophy, since he is investigating the necessary conditions of the possibility of meaning and experience. For Sami Pihlström, these last writings show that Wittgenstein, too, can be rightly called a 'pragmatist.' Their common position is "that it is only against the background of our human form(s) of life, of our habit of doing various things together in a common environment, that meaning and that learning is possible" (Pihlström 2004: 298).

of course, this kind of transcendental inquiry differs greatly from the classical Kantian approach. Wittgenstein is not inquiring into reason, but rather looks at our practical involvement as the 'framework,' or the 'transcendental ground,' which constitutes our thinking. Pihlström introduces the nice expression 'certainty-in-action' in order to illustrate this genuine practical dimension. Wittgenstein argues that language-games are grounded in our practical actions, in certainties which we do not doubt "in deed" (Wittgenstein 1969: sec. 342). He likens these "primitive reactions" to the act of taking hold of a towel (Wittgenstein 1969: sec. 510). In the beginning, we just do act in a certain way, and this is the condition for any subsequent linguistic refinement and normative assessment.

One particular subject where this transcendental argument comes to the fore is the practice of learning, which plays a central role in Wittgenstein's reflections. ${ }^{11}$ In order to learn at all how to normatively assess an utterance, to give it sense, we first have to learn to participate in the corresponding practice. This 'entry' into the language game, though, is not itself rationally structured. It begins with imitation and obedience. The student (the novice, the learner) first has to take for granted what the teacher tells her. "The schoolboy believes his teachers and schoolbooks" (Wittgenstein 1969: sec. 263). This is a logical condition. Without such an "ur-trust" (as Moyal-Sharrock calls it), there is no way to acquire the competencies which define a language-game. ${ }^{12}$ These competencies go beyond simple conditioning. They include forming an understanding of the point of the game, a shaping of interest, and minimally a perception of the salient properties which mark the actions and items of the language-game.

In the case of learning, we have a forceful illustration of how our "relation to the world and to others," as Cavell formulates it, "is not one of knowing." Training in the sense discussed here may include explanation, but firmly rests on non-epistemic factors such as bodily exercises, authority, trust, love, power, and of course the 'black box' of the individual (its talent, its wit, its capacity to understand what the teacher is trying to convey). We also have a good illustration of Wittgenstein's peculiar version of transcendentalism: If sense and meaning depend upon (among other things) training, the 
acquired "certainty-in-action" (Pihlström 2004: 299) indeed constitutes a background which is both necessary for understanding, and yet non-epistemic.

For this reason, Pihlström feels justified, as it has been remarked above, to include Wittgenstein on the list of those "pragmatized" versions of transcendentalism which examine "the conditions for the possibility of some given actuality [...] 'from within' the sphere (of experience, of meaning) constrained and limited by those conditions" (Pihlström 2004: 293). And the similarities to Dewey's 'empirical method,' which is looking at the ways we do in fact gain knowledge, cannot be denied. But there is an important difference which Pihlström ignores. In his argumentation, he continuously employs the first person in plural form. It is 'we' who investigate the (practical) limits of sense, and the conditions revealed are 'ours,' as are the practices. The inclusive 'we' is a common stylistic element in all attempts to offer a full-fledged transcendental reading of Wittgenstein, and it characterizes Dewey's style as well. But this position, in which the author assumes to be fully representative of the practice, misses Wittgenstein's insistent struggle to place the self, or the 'I,' within this 'we.' I take that to be Cavell's major discovery, which can be also identified in On Certainty. There we find numerous references to the problem how we, as individuals, become a part of the practice, and to what bars us from such a participation, respectively. As such, the topic of an irreducible tension between the practice and the subject who participates in the practice is introduced.

The prominent role of learning in Wittgenstein's remarks already illustrates this point. We have to learn in order to participate. That this process of learning is not an automatism upon which we can always rely - like a machine - is something which occupies Wittgenstein's reflections in the Philosophical Investigations (1967: sec. 208). A transcendentalist reading, like McDowell's (1984), would now point to the fact that we do in fact learn and convey meanings, and that accordingly any philosophical skepticism is just out of place. But this observation only captures one dimension of the normativity of practices: its objectivity. The subjective dimension shows up when Wittgenstein discusses, for example, those fundamental and often irreconcilable clashes of understanding where each party calls the other a fool or heretic (cf. Wittgenstein 1969: sec. 239,611$)$. On Certainty is not just interested in our certainties, but also explores their limitations. It confronts the reader with strange tribes, improbable evidence (like discovering sawdust in a head, sec. 211), men from Mars (sec. 430), mental disturbances (sec. 71), illusions (sec. 19), drugs (sec. 676) and straight out madness (sec. 355, 281, 674).

Here we touch on an important point. If it is true that any substantial doubt already presupposes a functioning language-game in which it can be judged, what then is the opposite of certainty? It is true that we agree, often, in language; this practical agreement is, as Wittgenstein had already remarked in the Investigations, fundamental for our capacity to understand each other. (Wittgenstein 1969: sec. 241) In these limit-cases of sense just quoted, this precondition of sense collapses. Considering that agreement forms a logical condition for the possibility of meaning, its lack cannot be stated in logically valid terms. It is not a simple contradiction. ${ }^{13}$

Doubt, as the contradictory of certainty, is something we can resolve by transforming it into a problem. This is Dewey's suggestion, the initial step of inquiry. But Dewey also emphasizes that in itself, doubt is too indeterminate to guide action. It is necessary to give it a definite form by qualifying it (cf. Dewey 2008: 111f.). The cases Wittgenstein discusses in On Certainty refuse such a determination. The lack of agreement cannot be 
qualified in an objective way since it implies a "revision," as Wittgenstein writes, which "would amount to an annihilation of all criteria"14 (Wittgenstein 1969: sec. 492).

31 In that sense, the opposite of certainty is not plain doubt, but that irritating sense of 'being wrong' which is more rightly associated with the onset of madness. On several occasions, Wittgenstein discusses the case that something which constitutes the ineliminable background of our understanding might be contradicted by everybody (cf. Wittgenstein 1969: sec. 614). Madness is looming there, since we cannot imagine how a world looks like in which these certainties are wrong. Wittgenstein emphasizes that this madness cannot be rejected by just pointing to the practice, since the certainty in question is essentially subjective:

I, L.W., believe, am sure, that my friend hasn't sawdust in his body or in his head, even though I have no direct evidence of my senses to the contrary. I am sure, by reason of what has been said to me, of what I have read, and of my experience. To have doubts about it would seem to me madness - of course, this is also in agreement with other people; but I agree with them. (Wittgenstein 1969: sec. 281)

Note that the cases of uncertainty Wittgenstein discusses are mostly not the philosopher's doubts. His favourite examples are children, madmen, historically shifting understandings or just strange confrontations with people whose convictions threaten 'our' certainties. These examples suggest that our life does not only consist of certainties, but also of that irritating evidence which challenges our self-understanding. Things like this happen, and they lead quite naturally - in deed, as Wittgenstein would say - to these seemingly "nonsensical" questions of how we, as individual subjects, can hold fast to the certainties that permeate our life.

Contrary to what the transcendental reading suggests, Wittgenstein is not assuring us that, in face of these doubts, 'we' do know what is right, and what is not. He rather probes our attitude towards certainty, traces it back to its origins (in learning), its conditions (social and natural), expressions and variations. A teacher might cut off a young student's doubt with the harsh remark to stop interrupting, since his doubts do not yet make any sense (Wittgenstein 1969: sec. 310). The grown-up philosopher, though, is not in the position of a novice. James Conant's reading (1998) that any skeptic or realist who tries either to prove the external world or to refute it, is uttering plain nonsense, devoid of any meaning, is not Wittgenstein's position. Wittgenstein is not assuming the teacher's position towards his fellow philosophers. Even though he clearly sees that Moore's attempt to prove the external world by raising his hands is nonsense, he does not content himself with that observation. He admits that these are attempts to "express something which cannot be expressed like that" and thus require "an investigation" in order to identify where the claim went wrong (Wittgenstein 1969: sec. 37; cf. sec. 76). The philosopher's nonsense has some sense, expresses something, even though it cannot be easily captured.

What emerges is a picture of a subject - "I, L.W." - which struggles with the certainty to which it finds itself bound from a logical point of view. ${ }^{15}$ This is what I mean by 'subjective' dimension of certainty. Wittgenstein is neither a skeptic nor is he assuming a plain transcendental position. The practically constituted certainties belong to the 'scaffolding' of our thoughts (Wittgenstein 1969: sec. 211), but it is a certainty in which we do trust, not something in which we can trust (cf. Wittgenstein 1969: sec. 509). The certainty which forms a condition of all thought is not a solid ground; it can be questioned, and this questioning - if it is more than an academic exercise - requires an 
investigation which assumes the form of an exploration. This observation helps to understand Wittgenstein's particular style of writing. Since our certainties are implied in our very subjectivity, putting forth arguments cannot do all the work. We have to try to show the other how we think they should think. And we should not believe that our own position is immune to doubts and misunderstandings, since the way we have learned the rules is itself dependent on an "indeterminate" (Wittgenstein 1969: sec. 28) practice: "Not only rules, but also examples are needed for establishing a practice. Our rules leave loopholes open, and the practice has to speak for itself" (Wittgenstein 1969: sec. 139).

In this section, we have seen in what sense the skeptic is 'disappointed' by knowledge. Wittgenstein is rejecting the common identification of knowledge with certainty, giving the latter priority. We might be certain that things are so and so, but this is not a knowledge to which we can appeal in the face of the irritating counter-evidence which Wittgenstein discusses. So there remains a gap between mind and world, a gap which does not call for more knowledge, but to a critical investigation of the place such knowledge plays in our life. These kind of 'inquiries' assume a completely different form than in the work of Dewey. Since the foundation of our practices is non-epistemic, we have to resort to non-epistemic means in order to clarify what it is we wanted to say, what troubles us, or how to counter the irritating evidence which threatens our very subjectivity. There is no definite form to these kinds of investigations; they should be rather thought of as constituting our intellectual life - devices such as conversation, analysis, comparison, exposure to new, strange or irritating experiences. The important point is that they cannot be thought of as simply enriching or correcting our present knowledge, but rather as ways to change the way we look at things, at ourselves and at others. They are, as I would like to put it, practices of the transformation of the self. Philosophy is one of these practices - it is, as Wittgenstein claims in "Culture and Value," a "work on oneself."

\section{Varieties of Practice}

Our comparison of Dewey and Wittgenstein's respective understandings of practice has revealed deep differences. For Dewey, practice, though inherently uncertain, also constitutes the certain ground to which we should turn if we seek - in the light of the irrefutable contingency - some orientation. This idea condenses in Dewey's conception of inquiry. The general pattern of inquiry is not just a practice, but also represents the very form of our coping with the world; its form remains identical, whether inquiry is performed collectively or individually. In this way, Dewey can argue that we should put all our trust into inquiry and its power to transform our experiences. The argument is transcendental: we cannot not inquire, so to inquiry we should turn in order to re-adjust our self-understanding. ${ }^{17}$

Wittgenstein, on the other hand, is offering two arguments against this rationalization of practice. He shows that our practical capacity to judge - the basis of inquiry - is itself grounded in non-rational relations ("an ungrounded way of acting," Wittgenstein 1969 sec. 110). Practices such as teaching assume non-epistemic means by which the subject, as Meredith Williams (2000) calls it, is 'calibrated' in order to acquire the normative contrast without which no sense is made. This includes behavioural conditioning, but extends to such "non-epistemic" influences such as trust, acknowledgment, and the whole range of means by which human beings govern each other. 
In a sense, this argument picks up a similar point as Dewey. Dewey's naturalistic pragmatism points to the 'integrated unity' of organism and environment, inferring that any reflection upon reflection has to take into account that this unity is the factual starting point, the transcendental basis, from which any further act of differentiation has to proceed. For Wittgenstein, this 'integrated unity' is better represented in the practice of learning. In learning, the individual assumes the norms, rules and "views" of the practice into which it is initiated. It is integrated in the 'environment' of practice. But contrary to Dewey, Wittgenstein does not believe that this logical unity holds fast over time. He allows for disturbances and overlapping claims, for irritating evidence and unforeseen individual confrontations. So Wittgenstein's second argument is that our initially acquired practical certainty, though in sense a transcendental condition of thought, can turn out to be 'wrong' in the sense of 'going mad' described above. Note the strict logical form this argument assumes: Our knowledge which is embedded in our practically acquired certainties cannot be used to prove or refute our relation to the world (and to others) precisely because our certainty does not reflect a prior state of the world, but rather constitutes the transcendental ground of sense and meaning.

This difference between Wittgenstein and Dewey boils down, I believe, to a diverging assessment of the sociality of practice. For Wittgenstein, practice is an essentially social form. This is why learning, as being something which requires someone else representing the constitutive norms of the practice, plays such a pivotal role. Belonging to a practice does not just mean to be involved in an activity, but also to be exposed to the judgments and expectations of the others. This dependency also implies a certain vulnerability, to which Wittgenstein was quite sensitive. After learning is done, this dependency does not disappear. It creates new problems which Wittgenstein discusses, for example, in On Certainty when everybody else openly contradicts you. Thus, the tension between the subjective position and the objective demands of the practice emerges, a tension which cannot be dissolved, but has to be explored.

For Dewey, the paradigm of practical activity is the individual (or organic) habit. Sociality is introduced as a new environment, thus retaining the general ecological logic of interaction between organism and environment. ${ }^{18}$ Language, or communication, is defined as the collective use of signs in order to attain shared experiences. Dewey describes meaning as a "community of partaking" (Dewey 1981: 146), caused by the joint use of symbols. Disagreement, accordingly, is just a failure of coordination and does not form a substantial threat to meaning and understanding. It is at this point that the contrast to Wittgenstein stands out most clearly. Both agree that language presupposes agreement in order to function. But for Wittgenstein, this is a logical insight, which consequently allows for the possibility of a mismatch between our inculcated subjective logical certainties and their objective practical realisation. For Dewey, this agreement is an objective presupposition, the failure of which causes confusion and weakens our intellectual powers, but does not weaken the general conviction that our practice is, as it is, a secure foundation of all thinking. 


\section{BIBLIOGRAPHY}

ALlen B., (2004), Knowledge and Civilization, Boulder, Westview Press.

BLUmenberg H., (1983), The Legitimacy of the Modern Age, Cambridge, Mass., MIT Press.

BRANDOM R., (2003), "Pragmatics and Pragmatisms," in Hilary Putnam, Pragmatism and Realism, J.

Conant \& U. Szeglen (eds.), London, Routledge.

CAVELl S., (1979), The Claim of Reason, Oxford, Oxford University Press.

CAVELl S., (2004), Cities of Words. Pedagogical Letters on a Register of the Moral Life, Cambridge, Mass., Harvard University Press.

DEWEY J., (1981), Experience and Nature, LW 1, Carbondale, Southern Illinois Univeersity Press.

DEWEY J., (1983), Human Nature and Conduct, MW 14, Carbondale, Southern Illinois University

Press.

DEWEY J., (1988), The Quest for Certainty, LW 4, Carbondale, Southern Illinois University Press.

DEWEY J., (2008), Logic, LW 12, Carbondale, Southern Illinois University Press.

DIAMOND C., (1991), The Realistic Spirit: Wittgenstein, Philosophy, and the Mind, Cambridge, Mass, MIT

Press.

GARRISON J., (1995), “Dewey's Philosophy and the Experience of Working: Labor, Tools and Language," Synthese, 105 (1).

Goodman R., (2002), Wittgenstein and William James, Cambridge, Cambridge University Press.

MCDOWELL J., (1984), “Wittgenstein on Following a Rule,” Synthese, 58 (3).

MOYAL-SHARROCK D., (2004a), Understanding Wittgenstein's “On Certainty,” Basingstoke, Palgrave.

MOYAL-SHARROCK D., (ed.), (2004b), The Third Wittgenstein: The Post-Investigations Works, Aldershot, Ashgate.

MOYAL-SHARROCK D., \& BRENNER (eds.), (2007), Readings on Wittgenstein's “On Certainty,” Basingstoke, Palgrave.

PIHLSTRÖM S., (2004), “Recent Reinterpretations of the Transcendental," Inquiry, 47 (3).

PINKARD T., (1999), “Analytics, Continentals, and Modern Skepticism,” Monist, 82 (2).

VOLBERS J., (2009), Selbsterkenntnis und Lebensform: Kritische Subjektivität nach Wittgenstein und Foucault, Bielefeld, transcript.

WILLIAMS M., (1999), “The Philosophical Significance of Learning in the Later Wittgenstein," in Wittgenstein, Mind and Meaning, M. Williams (ed.), London, Routledge.

WiLliAms M., (2000), "Wittgenstein and Davidson on the Sociality of Language," Journal for the Theory of Social Behaviour, 30 (3).

WITTGENSTEIN L., (1967), Philosophical Investigations, Oxford, Blackwell.

WITTGENSTEIN L., (1969), On Certainty, Oxford, Blackwell. 
WITTGENSTEIN L., (1980), Culture and Value, Oxford, Blackwell.

WitTGENSTEIN L., (1983), Remarks on the Foundations of Mathematics, Boston, MIT Press.

WITTGENSTEIN L., (2000), Wittgenstein's Nachlass, Bergen Electronic Edition, Oxford, Oxford

University Press.

VON WRIGHT G. H., (1982), “Wittgenstein in Relation to his Times," in B. McGuinness (ed.),

Wittgenstein and his Times, Blackwell, Oxford.

\section{NOTES}

1. Brandom's family picture includes Kant, Peirce, James, Dewey, Heidegger, Wittgenstein, Quine, Sellars, Davidson and Rorty - and of course, himself (Brandom 2003: 40).

2. Cora Diamond, for example, exclaims that calling Wittgenstein's philosophy inherently conservative is just 'nutty' (Diamond 1991: 34).

3. 'Wissen ist ein Können' (MS 164 from the Bergen Edition (2000), dated 1941).

4. Cf. in addition to the following also Ch. 4 of Dewey's Experience and Nature (Dewey 1981: 100-31).

5. Garrison 1995 accordingly sees the 'experience of working' as the key to understand Dewey and profitably compares this idea with the early works of Hegel.

6. This thesis has also been defended by Hans Blumenberg 1983, who argues that scientific progress is exactly due to the abandonment of speculative reflection. A more contemporary elobaration of the philosophical implactions of this idea can be found in Allen 2004.

7. Cf. Dewey (2008: 48-65).

8. Terry Pinkard 1999 argues that in fact all philosophy of the 20th century, analytic, postanalytic as well as continental, has been driven by modern "experience of skepticism."

9. John McDowell 1984 shows that Kripke's reading of Wittgenstein as a skeptic must fail.

10. For an overview of the different views on On Certainty, cf. Moyal-Sharrock \& Brenner 2007. For a discussion of the 'third Wittgenstein,' cf. Moyal-Sharrock $2004 \mathrm{~b}$.

11. As Meredith Williams 1999 has argued, the topic of learning is essential both to understanding the Philosophical Investigations and On Certainty.

12. Cf. Moyal-Sharrock (2004a: 97).

13. Cf. Wittgenstein (1983: sec. VI-49).

14. Anscombe translates the German original "Maßstäbe" with "yardsticks"; I amended the translation since Wittgenstein is talking here of criteria in general. This being said, the yardstick is Wittgenstein's favorite metaphor for these kind of judgments which are immune to doubt because they constitute the way we assess normative contrasts (Williams 1999).

15. 'One might say: 'I know' expresses comfortable certainty, not the certainty that is still struggling” (Wittgenstein 1969: 357).

16. Wittgenstein (1980: sec. 16e). I develop this position more fully in my Selbsterkenntnis und Lebensform (2009) which argues that Wittgenstein's conception of philosophy is assuming the traditional form of a 'spiritual exercise,' as Pierre Hadot calls it, and I extend this conception with Foucault's notion of a 'practice of the self.'

17. Dewey's thinking here is Hegelian in form and spirit. The following quote, for example, echoes the Hegelian idea that we are not just contingent byproducts of nature, but rather embody a necessary dialectical step in the continous process in which the absolute (or nature) tries to overcome its self-alienation through the means of self-knowledge: "In modern science, learning is finding out what nobody has previously known. It is a transaction in which nature is teacher, and in which the teacher comes to knowledge and truth only through the learning of the inquiring student" (Dewey 1981: 122). 
18. "We may say [...] that natural operations like breathing and digesting, acquired ones like speech and honesty, are functions of the surroundings as truly as of a person. They are things done by the environment by means of organic structures or acquired dispositions. The same air that under certain conditions ruffles the pool or wrecks buildings, under other conditions purifies the blood and conveys thought" (Dewey 1983: 15).

\section{ABSTRACTS}

Even though both Dewey and Wittgenstein have been rightly classified as both being 'pragmatist' thinkers in a broad sense, they stand in stark contrast with respect to their writing style and their general attitude towards the future of western civilization. This article reflects these differences and traces them back to their diverging conceptions of knowledge. Dewey criticizes the philosophical tradition for erecting an artificial barrier between theory and practice, but he retains the traditional high esteem for knowledge by re-describing it as practical inquiry. Consequently, all practically acquired beliefs and certainties are either justified or a potential subject-matter for further inquiries. Wittgenstein, on the other hand, shows the limitation of the very idea of knowledge by pointing to the knowing subject's fragile relation to its own lived practices. He claims that there are practically acquired beliefs and certainties which are out of reach for the inquiring subject. Thus, the seemingly superficial divergence in style and method shows to be grounded in far-reaching philosophical differences.

\section{AUTHOR}

\section{JÖRG VOLBERS}

\section{FU Berlin}

jvolbers[at]zedat.fu-berlin.de 